\title{
The use of modelling in design of wastewater subsurface drip irrigation
}

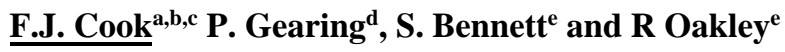 \\ ${ }^{a}$ Freeman Cook \& Associates Pty Ltd, ${ }^{b}$ School of Food and Agriculture, The University of Queeensland, \\ ${ }^{c}$ Australian Rivers Institute, ${ }^{c}$ Griffith University, ${ }^{d}$ NexGen Water Ltd, New Zealand, ${ }^{e}$ Stantec Dunedin, New \\ Zealand, \\ Email:freeman.j.cook@gmail.com
}

\begin{abstract}
A methodology for the use of modelling in designing a wastewater land treatment scheme is presented. This uses analytical models to determine the depth and spacing of the drippers. From the dripper spacing and the wastewater volume the number of drippers, the area to be irrigated can be calculated an $\mathrm{d}$ a provisional design developed. The wastewater nitrogen concentration along with the average plant uptake was used to estimate the timing between irrigations. This led to further refinement of the provisional design with the number of blocks in the irrigation area and engineering layout such as valves etc.
\end{abstract}

The results from the analytical modelling were used to determine the spatial domain for the numerical modelling and an a few initial layouts. The numerical modelling used HYDRUS2D with axisymmetric coordinates and was run for a 7 year period. This approach allows the different layouts to be tested against the consent requirements. A flow chart of the systematic approach taken is shown in figure 1 .

This approach was used for the Te Anau subsurface dripper irrigation (SDI) scheme, which is used as an example. The consent requirement was based on the leaching of nitrogen beyond a depth of $2 \mathrm{~m}$. The sensitivity of the results to the depth and spacing between the drippers and the time between wastewater irrigations showed that only the spacing had a significant effect on the nitrogen leaching.

The results from the numerical modelling were used to design the final layout and the area required for irrigation and accompanying ungrazed area. The ungrazed area required to achieve a nitrogen load to the groundwater below a consent level was determined using the results from the modelling. The methodology used here of incorporating both analytical and numerical modelling in designing a wastewater land treatment scheme offers a systematic approach to design such schemes.

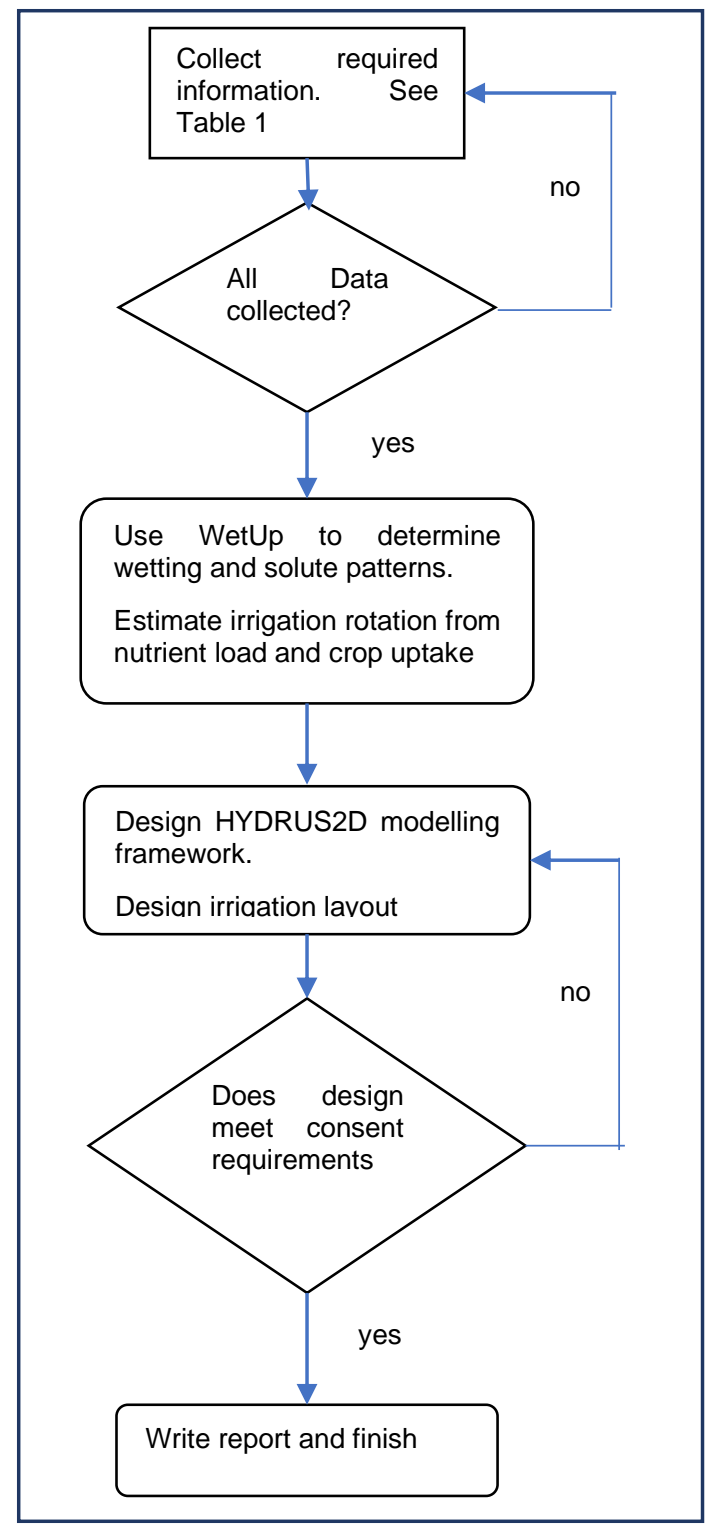

Figure 1. Flowchart for wastewater subsurface irrigation design

Keywords: Land treatment, wastewater, HYDRUS2D, subsurface drip irrigation, modelling 


\section{INTRODUCTION}

The reuse of wastewater (especially domestic wastewater) is an important resource for both the water and nutrients it contains. There has been a move to start and apply wastewater to land rather than discharge to ocean or river outfalls. The composition of domestic wastewater has been reviewed by Tjandraatmadia et al. (2010) and Cornejo et al. (2016) looked at the water reuse, energy recovery and nutrient recycling of wastewater treatment from household scale to city scale. Subsurface drip irrigation is used with household septic tank systems and for larger applications such as golf courses or other applications. Cornejo et al. (2016) found that the scale of the system effected the beneficial effects of wastewater reuse.

There are a number of ways to ensure that the system meets the environmental and regulatory conditions. One way is to have conservative regulatory constraints on the daily wastewater application in terms of volume per unit area (depth of application) which is the approach taken by many Regional Authorities in New Zealand for household (septic tank) systems (Barnett and Ormiston, 2009). This approach does not fully utilize the potential benefit that may arise from the wastewater and as it does not take into account climate and may be subject to failure (https://thisnzlife.co.nz/7-common-reasons-

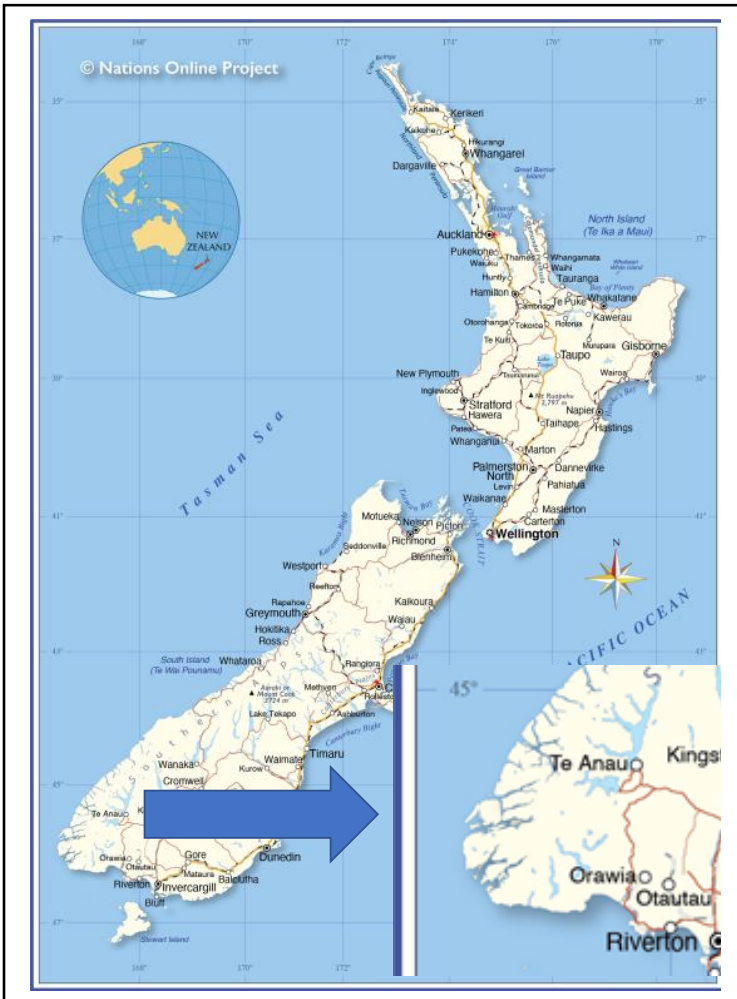

Figure 2. Location of the Te Anau, New Zealand septic-tank-fails/). At all scales the impacts of water reuse were found to be greater than the impacts of nutrient recycling and energy recovery (Cornejo et al. 2016). In implementing a recycling usage of wastewater it is important that this meets the requirements of the community it is to serve, the regulatory requirements and environmental concerns. Here we present a systematic approach to development of optimal design of subsurface drip irrigation (SDI) for wastewater.

This approach was used for the design of discharge of wastewater from the township of Te Anau in the South Island of New Zealand was discharged following tertiary treatment to the Upukeroroa river and then into lake Te Anau and is used as an example here. Following community concerns about the use of a travelling irrigator SDI was chosen as the wastewater irrigation system. This required a change in the water and nutrient transport models from one to three spatial dimensions. Here we will present a modelling procedure that was used to design a wastewater irrigation system for a community scale system for the township of Te Anau in the South Island of New Zealand (Figure 2).

\section{METHODS}

The methods we used are a combination of analytical and numerical modelling.

\subsection{Initial analytical modelling}

The first step in the process is to gather all the required data to allow for the analysis. The data requirements are given in Table 1 and the source of data for the Te Anau system shown. 
Cook et al., The use of modelling in design of wastewater subsurface drip irrigation.

\begin{tabular}{|l|l|l|l|l|l||}
\hline Table 1. Properties required for modelling wastewater SDI design \\
\hline Property type & Property & Source & Property type & Property & Source \\
\hline Soil physical & Layer thickness and depth & Davoren (2013) & Plant & Growth & Davoren (2013) \\
\cline { 2 - 6 } & Bulk density & Davoren (2013) & & Uptake & $\begin{array}{l}\text { McIndoe } \\
\text { Von Wiren et al. } \\
(2001)\end{array}$ \\
& Moisture release \\
& characteristics & Davoren (2013) & Climate & Rainfall & NIWA \\
\cline { 2 - 7 } & Hydraulic conductivity & Davoren (2013) & & PET & NIWA \\
\hline Soil chemical & Cation exchange capacity & S-MapS & Wastewater & Flow & Stantec \\
\hline & Nitrogen concentration & Davoren (2013) & & $\begin{array}{l}\text { Nitrogen } \\
\text { concentration }\end{array}$ & Stantec \\
\hline & Denitrification rate & $\begin{array}{l}\text { Radcliffe and } \\
\text { Simunek (2010) }\end{array}$ & Plant & Growth & Davoren (2013) \\
\hline & Ammonia retardation & $\begin{array}{l}\text { Vogeler et al. } \\
\text { (2011) }\end{array}$ & & Uptake & $\begin{array}{l}\text { McIndoe } \\
\text { Von Wiren et al. } \\
(2001)\end{array}$ \\
\hline
\end{tabular}

Using the gathered data, initial modelling using analytical models to get an estimate of the likely wetting patterns and mass balances is undertaken and a range of initial layouts developed. The models used for this are given in Table 2.

Table 2. Initial modelling procedure for SDI HYDRUS2D modellinglayout design.

\begin{tabular}{||l|l|l|l|l|}
\hline Item & Model & Data Requirements & Output & Reference \\
\hline $\begin{array}{l}\text { Wetting } \\
\text { patterns }\end{array}$ & WetUp & $\begin{array}{l}\text { Soil physical properties, } \\
\text { dripper flow rate }\end{array}$ & $\mathrm{Z}^{+}, \mathrm{Z}^{-}, \mathrm{R}$ & Cook et al. (2007) \\
\hline $\begin{array}{l}\text { Solute } \\
\text { patterns }\end{array}$ & Wet Up & $\begin{array}{l}\text { As above plus, } \\
\text { wastewater } \\
\text { concentrations, CEC }\end{array}$ & $\mathrm{Z}_{\mathrm{c}}^{+}, \mathrm{Z}_{\mathrm{c}}^{-}, \mathrm{R}_{\mathrm{c}}$ & Cook (2017) \\
\hline Rotation & Spreadsheet & $\begin{array}{l}\text { Plant uptake, mass of } \\
\text { solute added per } \\
\text { irrigation }\end{array}$ & $\begin{array}{l}\text { Time between } \\
\text { irrigations }\end{array}$ & \\
\hline
\end{tabular}

\subsection{Preliminary design}

In order to move forward further data is required for the preliminary design:

- At least 5 years of climate data. This may require some extrapolation if there are no adjacent climate stations. Software tools to do this are available now in many countries.

- Soil physical properties such as the moisture retention characteristics, hydraulic conductivity, bulk density and particle size distribution for each layer in the soil profile.

- Chemical composition of wastewater.

- Volume of wastewater, mean daily volume, maximum volume.

- Area of land available for wastewater application.

- Crop uptake of solutes of interest.

From the preliminary modelling we now have design criteria of dripper spacing between drip lines and between drippers along each line and depth of burial at a depth. The depth of wetting and solute transport for a single irrigation are estimated and used in the design of the two-dimensional axisymmetric domain in HYDRUS2D. 
Cook et al., The use of modelling in design of wastewater subsurface drip irrigation.

\section{RESULTS}

The results for the modelling of the SDI system for Te Anau will be used to illustrate the systematic approach to SDI design advocated here.

\subsection{Preliminary design}

An example of the wetting and solute (retarded solute) patterns and using the WetUp model are shown in Figure 3, (Cook, 2019). These results are used to estimate the depth of placement of the dripper. We do not want the solutes to reach the soil surface so for the example in Figure 2 a depth of placement $>0.15 \mathrm{~m}$ would be appropriate with an applied volume of $8 \mathrm{~L}$. The radial wetting for this volume is approximately $0.3 \mathrm{~m}$, so this gives an estimated dripper spacing of $0.6 \mathrm{~m}$. The depth of wetting below the dripper would be approximately $0.6 \mathrm{~m}$ which combined with the depth of the dripper would give a wetting depth of $0.75 \mathrm{~m}$. The solute depth front, especially for a retarded solute, would be considerably less at about $0.3 \mathrm{~m}$. These estimates though are for a single irrigation and do not account for frequent irrigations, climate and plant factors.
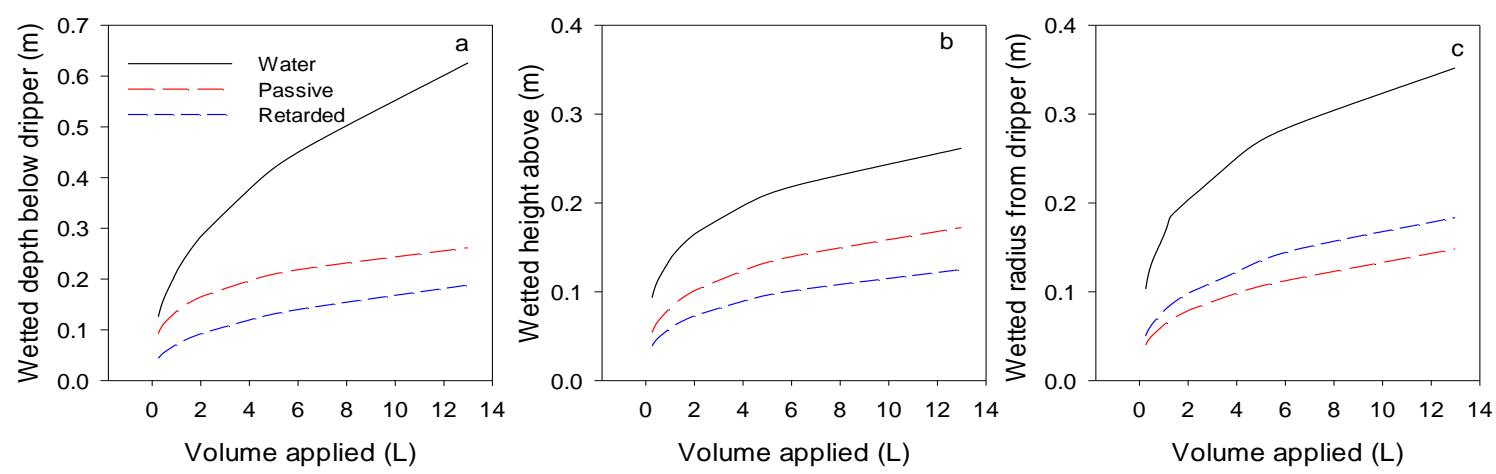

Figure 3. Wetted perimeters with the volume applied for water, passive solute and retarded solute a) depth below dripper, b) height above dripper and c) radius from dripper calculated with WetUp.

To estimate the return period for the irrigation we need data on the plant uptake of the solutes of interest, usually nitrogen or phosphorus. For this land treatment the wastewater solute of interest was nitrogen and as the groundwater from the area chosen discharges into Lake Manapouri the leached concentration had to be below a critical value. This critical value had been set by earlier modelling for spray irrigation using the OVERSEER model (https://www.overseer.org.nz/o ur-model) in the environmental consent process.

Using the average nitrogen uptake for an applied volume of $8 \mathrm{~L}$ the nitrogen could have been taken up by the plant in 8

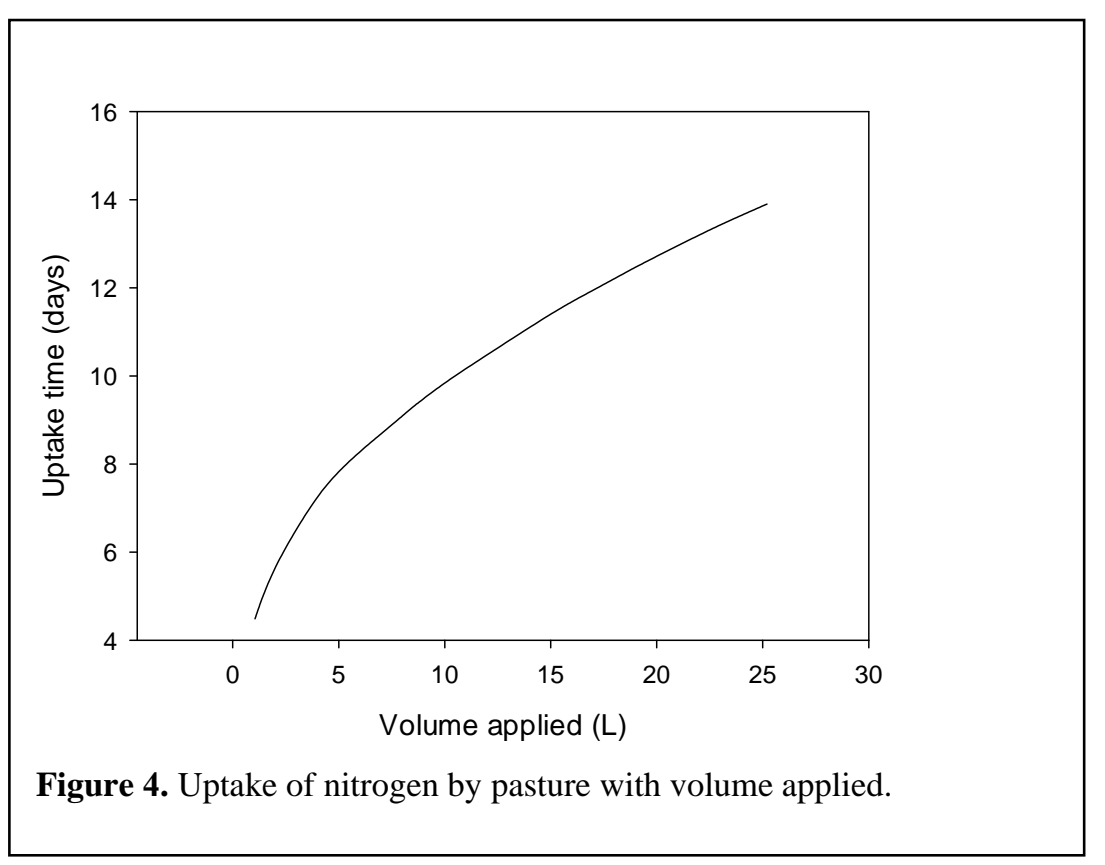


Cook et al., The use of modelling in design of wastewater subsurface drip irrigation.

days (Figure 4). This is a simplistic estimate which assumes no other sources of nitrogen. An 8 day rotation is also likely to allow the oxygen demand for breakdown of the wastewater to have dissipated (McAuliffe et al.1982).

\subsection{Detailed modelling with HYDRUS2D}

From the preliminary design the area (A) total number of drippers (Td), dripper flow rate (q), daily volume

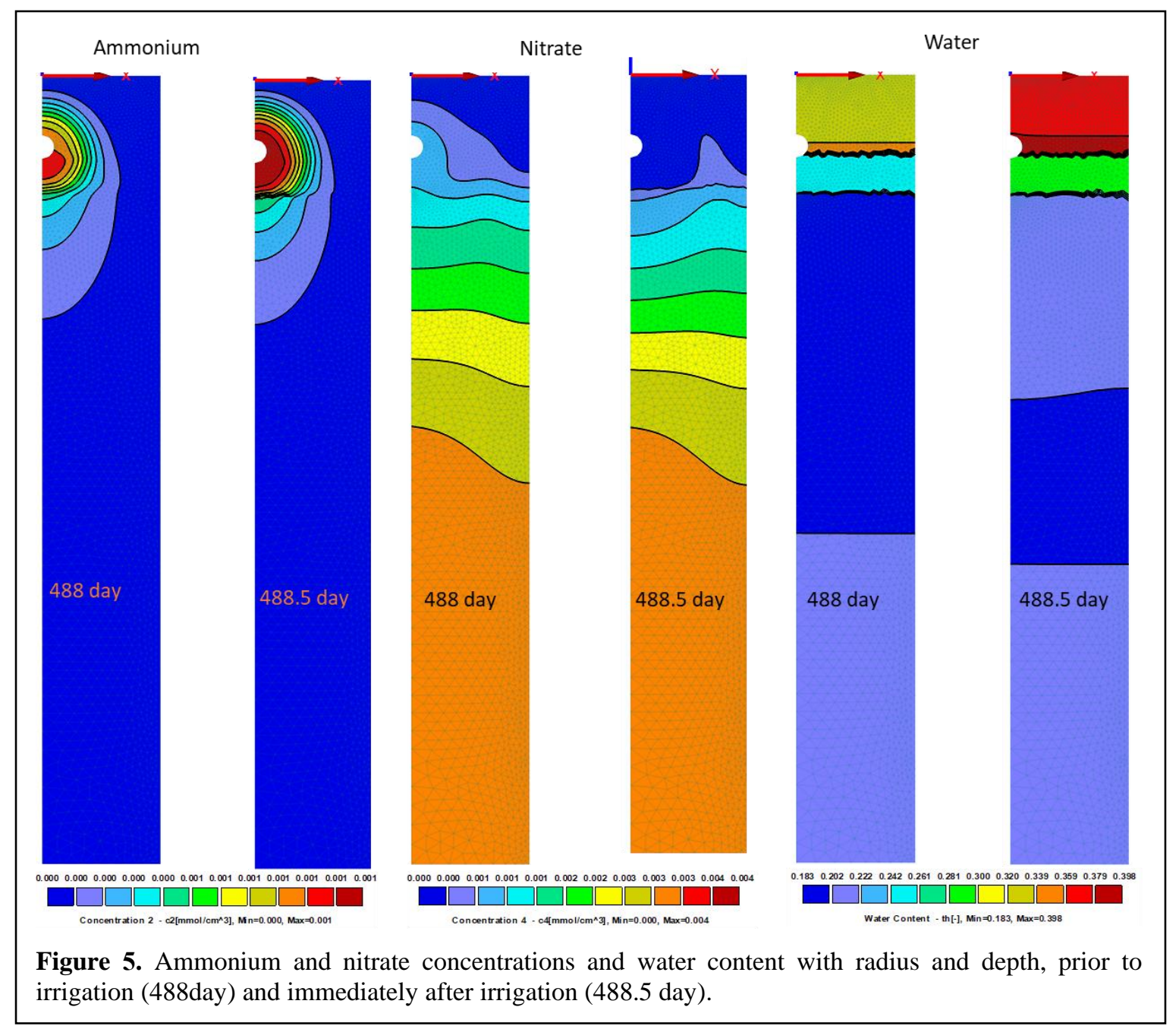

of application (V), time of application (ti) and return period for a block of drippers (tr) is calculated. The input data required was obtained from various sources which are given in Table 1. From this data we were able to calculate the simulated; evapotranspiration, drainage, plant nitrogen uptake and leached nitrogen as a function of time. The simulations were run for 2558 days. The distribution of ammonia, nitrate and water prior to an irrigation and following an irrigation show how the retardation of ammonium results in less transport both vertically and horizontally compared to nitrate, while the water content is approximately one dimensional with only vertical variation (Figure 5). From the modelling we can obtain the amount of nitrogen leached beyond the rootzone. The nitrogen leached varies with time due to the climate inputs with the seasonal effect showing with the sinusoidal effect and the random pulses due to rainfall (Figure 6a). The cumulative effect is more constant with close to a linear increase with time (Figure 6b).

\subsection{Sensitivity to dripper placement}


Cook et al., The use of modelling in design of wastewater subsurface drip irrigation.

The sensitivity of the nitrogen leaching with dripper depth and spacing, and time between irrigations was simulated. The leaching increased with a decrease in dripper spacing and was only slightly affected by dripper depth or the time between irrigations (Figure 7). The affect of the time between irrigations does not
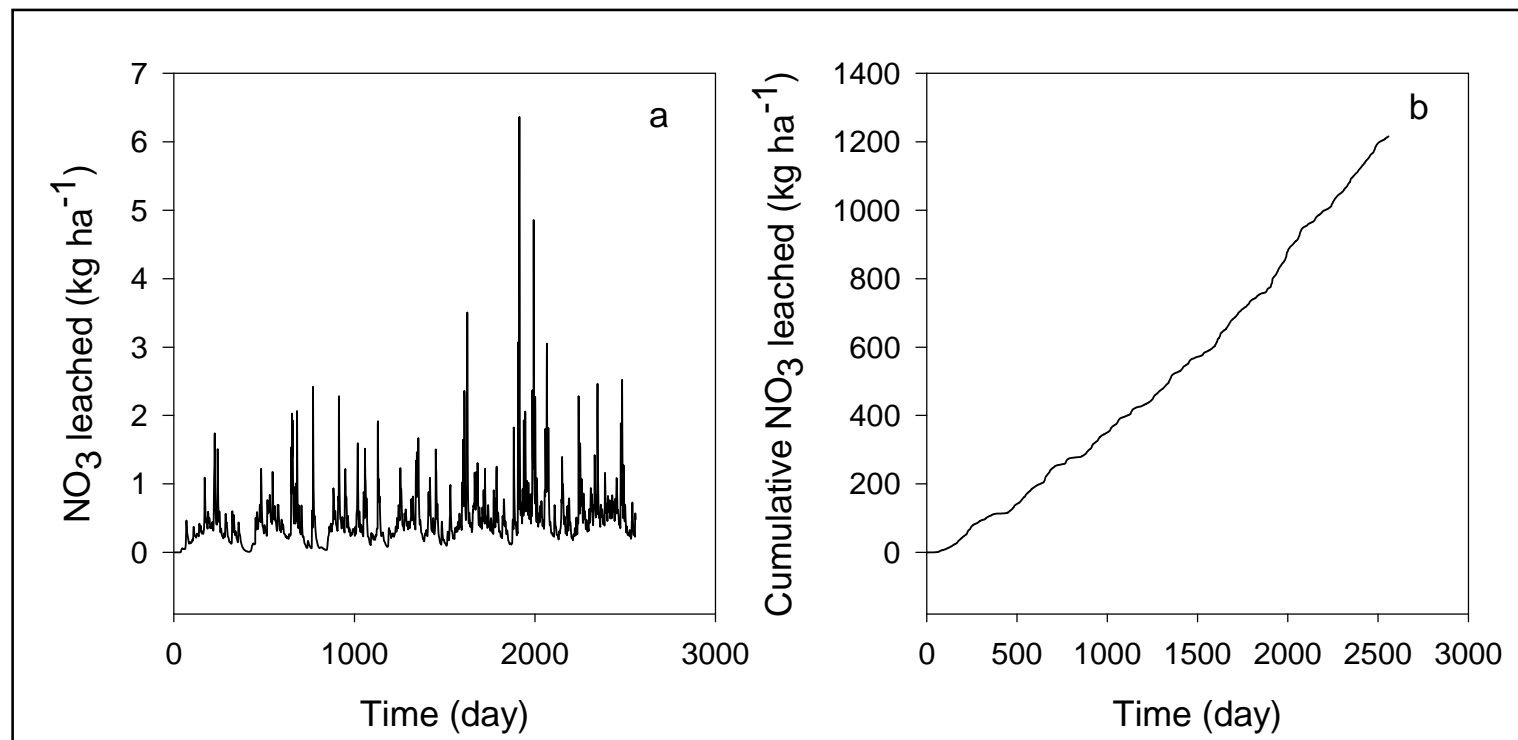

Figure 6. Nitrogen a) leached beyond $2 \mathrm{~m}$ depth with time and b) cumulative nitrogen leached with time.

take into account any effect of bacteria blockage of the pore space by too frequent irrigation with a carbonaceous wastewater. Thus an 8 day irrigation rotation was selected as this was the best compromise between the practical considerations of the irrigation layout and nitrogen leaching.

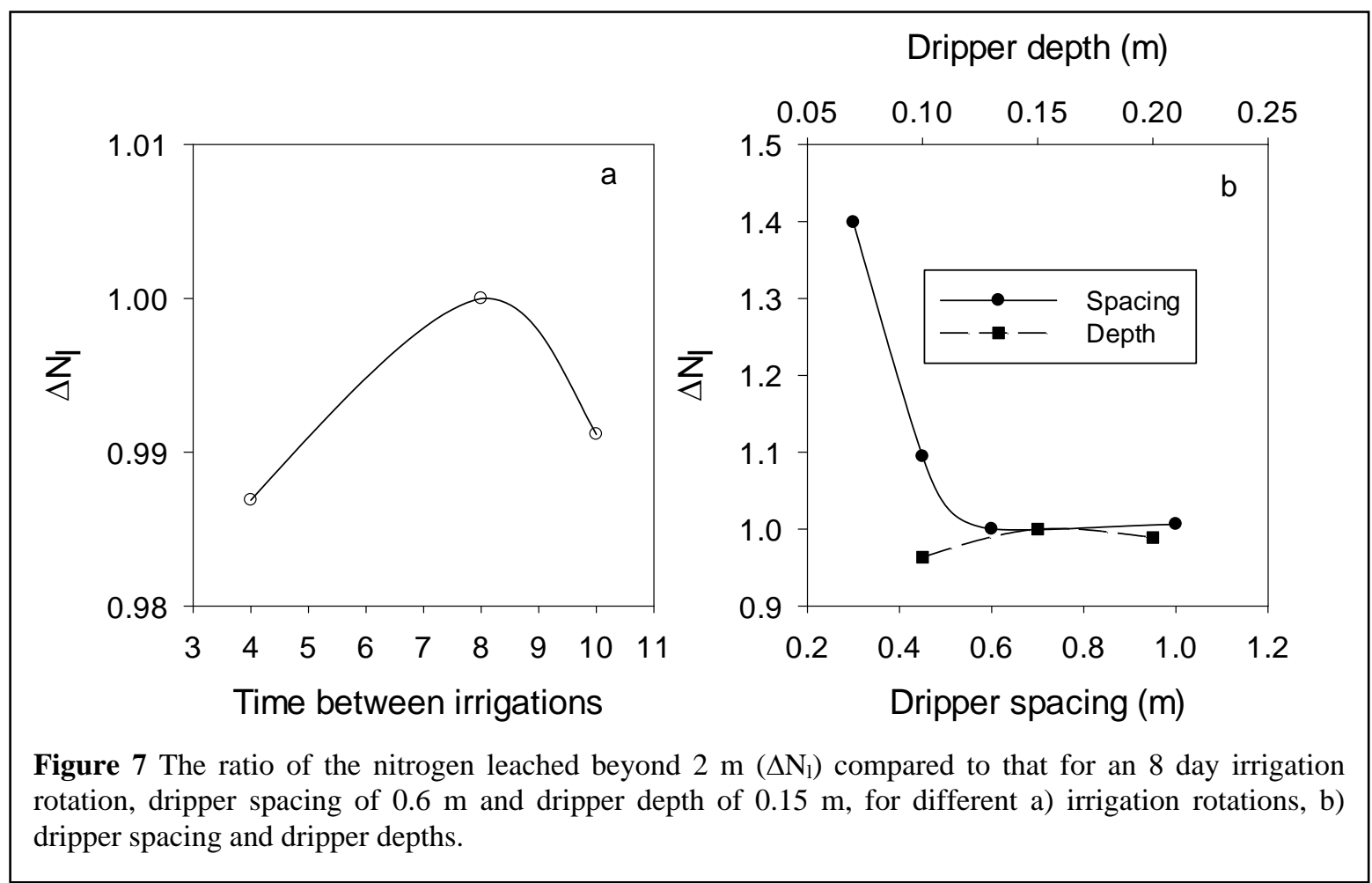

\section{DISCUSSION}

The requirement for the consent for this land treatment scheme was that it should not exceed an earlier consented proposal using spray irrigation that resulted in a nitrogen loading to the ground water of a set amount $\left(N_{l} \mathrm{~kg}_{-} \mathrm{N} \mathrm{yr}^{-1}\right)$. This scheme was going to be implemented on a site which is presently grazed and would have an estimated leaching rate of $R N_{g}\left(\mathrm{~kg}_{-} \mathrm{N} \mathrm{ha}{ }^{-1} \mathrm{yr}^{-1}\right)$. A proportion of this area would be used for the 
Cook et al., The use of modelling in design of wastewater subsurface drip irrigation.

land treatment scheme and the remainder would be left as a ungrazed with not fertilizer inputs. The nitrogen leaching rate $\left(R N_{u} \mathrm{~kg} \mathrm{ha}^{-1} \mathrm{yr}^{-1}\right)$ for the ungrazed area was estimated using simulations with HYDRUS1D. Further grazed pasture could be converted to ungrazed status if required. This total area of the scheme including the ungrazed area was calculated by:

$$
A_{T} \geq\left[A_{I}\left(R N_{I}-R N_{u}\right)-N_{L}\right] /\left(R N_{g}-R N_{u}\right)
$$

where $R N_{I}$ is the rate of nitrogen leaching from the irrigated area $\left(\mathrm{kg}_{-} \mathrm{N} \mathrm{ha} \mathrm{hr}^{-1} \mathrm{yr}^{-1}\right), A_{T}$ is the total area required (ha) and $A_{I}$ is the area irrigated (ha). This allowed the size of the area required to meet the consent and the layout of the irrigation area to be finalized. Using this systematic approach allowed the Te Anau scheme to satisfy the regulatory agency's consent requirements. The design has now be implemented and is presently being commissioned.

\section{CONCLUSION}

A procedure using modelling as a method for designing a wastewater land treatment scheme has been successful used. This consists of:

- Initial design using simple analytical models to determine the possibilities for more detailed modelling,

- Detailed modelling using, for subsurface irrigation considered here, HYDRUS2D with axisymmetric coordinates,

- Development of the final design to meet the consent requirements for the scheme.

\section{REFERENCES}

Barnett, H. and Ormistron S. (2009). Manual for on-site wastewater systems design and management. Horizons Regional Council New Zealand. Version 2, 113pp.

Cook, F.J. 2019. Modelling nitrogen leaching from subsurface drip irrigation for Te Anau waste water upgrade. Freeman Cook \& Associates, 34pp.

Cornejo, P.K., Zhang, Q. and Mihelici, J.R. (2016). How does scale of implementation impact the environmental sustainability of wastewater treatment integrated with resource recovery? Environmental Science \& Technology 50: 6680-6689.

Davoren, T (2013). Kepler farm waste water irrigation: Site and irrigation assessment. Prepared bt Dr Antony Davoren Hydroservices, April 2013, 67pp.

McIndoe (2018). Te Anau waste water upgrade: SDI versus CPI comparison. Southland District Council Water \& Waste Services,6. Aqualinc Research Limited, 20pp.

Radcliffe DE and Simunek J (2010) Soil Physics with HYDRUS: Modelling and Applications. CRC Press, Taylor and Francis, Boca Raton, 372pp.

Simunek et al. (2012). van Genuchten M Th and Šenja M (2012). The HYDRUS software package for simulating two- and three dimensional movement of water, heat and multiple solutes in variably-saturated porous media. Version 2.0, Technical Manual, PC Progress, Prague, Czech Republic, 258p.

Tjandraatmadja, G., et al. (2010). Sources of contaminants in domestic wastewater: nutrients and additional elements from household products. Canberra, Australia, CSIRO: Water for a Healthy Country: 118pp.

Vogeler, L., Cichota, R., Snow, V.O., Dutton, T. and Daly, B. (2011). Pedotransfer functions for estimating ammonia adsorption in soils. Soil Sci. Soc. Am. J., 75(1): 324-331.

von Wirén N., Gojon A., Chaillou S. and Raper D. (2001) Mechanisms and Regulation of Ammonium Uptake in Higher Plants. In: Lea P.J., Morot-Gaudry JF. (eds) Plant Nitrogen. Springer, Berlin, Heidelberg. 